\title{
The Application and Thinking of Business and Finance Integration under the Internet Plus
}

\author{
Yurong Gao \\ Shandong Women's University \\ Jinan Shandong 250010
}

\begin{abstract}
Under the background of the Internet Plus, business and finance integration is an irresistible trend for economic development. It integrates business and financial affairs with the aid of information technologies, so as to transform the role of finance from accounting passively to value creating. It can back up the management decision for better serving the enterprise. This paper analyzed the necessity of integrating business and finance under the Internet Plus, pointed out the difficulties in the current process and based on which put forward suggestions on promoting the integration for improving the quality of finance-business integration.
\end{abstract}

Keywords-Internet Plus; financial accounting; finance and business integration

\section{INTRODUCTION}

"Internet Plus" refers to the application of the internet in other conventional industries. In the ear of "Internet Plus", enterprises should utilize information technology and internet platform to create new development possibilities. With the rapid development of internet technology, artificial intelligence and big data, profound changes will take place in the concept, function and method of accounting. As various enterprises are establishing the Financial Shared Service Center, the accounting profession is undergoing huge changes. In June, 2016, the ministry of finance released the Basic Guidelines for Management Accounting which specified that to apply management accounting, organizations need to adhere to the principle of unity, and the management accounting should be embedded in the relevant fields, levels and links of the organization. In addition, the finance and business should be organically integrated with the management accounting tools and methods based on business processes. Since then, enterprises are actively exploring and attempting the integration of finance and business. In particular, as our country calls to deleverage and reduce cost under the background of the sharing economy and the supply-side structural reform, financial accounting will inevitably transit from passive accounting to the actively create value. On in this way, can it give full play to the functions in financial supervision and management decision support. In the circumstances, finance and businesses integration is an important task for enterprises.

\section{The NECESSITY OF INTEGRATING BUSINESS AND FINANCE}

Traditional accounting is generally conducted after business activities, which cannot effectively support decisionmaking. Business-and-finance integration refers to the timely sharing of business flow, capital flow, information flow and other data sources between business departments and financial departments through information technology and means, based on which the two sides make joint efforts in decision-making, control and evaluation of management activities based on value objectives, so as to realize the enterprise value creation. The organic integration of finance and business has become the key to the transformation from financial accounting to value creation. Internet Plus has ushered in the era of big data, accompanied by the increasingly open and shared information resources. Information communication between enterprises and the external environment and among various departments within enterprises becomes more extensive and faster. In the era of big data, anyone can take the initiative in the competition if he obtains sufficient, effective information in a timely manner.

In the ear of Internet Plus, it is necessary to implement the integration of the business and the finance. First of all, it can maximize the effectiveness of the resources by optimizing the resource allocation in enterprises, so as to improve the business efficiency of enterprises. What's more, the financial department can engage in the business managing activities to keep a close eye on the budget by acquiring the business data, and to put forward suggestions as soon as it detects the internal control flaws. In this way, it is possible to reduce the risks of enterprises and complete the risk warning mechanism. Finally, with the integration, the financial department can timely and effectively budget the cost to maximize the utility of economic resources, thus realizing the maximization of enterprise value.[1]

\section{DIFFICULTIES IN BUSINESS AND FINANCE INTEGRATION} UNDER THE INTERNET PLUS

\section{A. Different goals and priorities of the business and financial sectors}

Business sector and financial sector in an enterprise do not share the same goals. On the one hand, business sector aims to achieve business indicators, so its focus is mainly around the performance. Sometimes, it may pay more attention to the 
completion of indicators while neglecting the cost and risk of the enterprise. On the other hand, financial sector which is responsible for value management, entails the goal to enhance the profit rate of capital and control risks of the enterprise by curbing the costs and expense, so as to maximum the enterprise value. That is to say, financial sector pays much attention on the profitability and risk control. Therefore, the differences in the working purpose and priority impede the integration of finance and business. [2]. In fact, while setting targets, the two sectors do not care about each other, or refer to other's objectives, which results in the fact that the goals of the two sides go far from each other.

\section{B. Without strong data support for business and finance integration}

In order to achieve the integration of business and finance, enterprise financial department should have access to business data, and the financial management of enterprises should be extended to the front end of the business. Only when the business data can automatically and directly generate financial data, can financial personnel realize the pre-analysis, judgment and audit of business activities. But some companies relied too much on information technology in establishing information system, which makes the financial system fail to satisfy the requirement of the finance for the business data. In addition, business activities are diverse and complex with varied encoding schemes for business data. Given this, it is hard for information system to extract data, impeding the communication between business data and financial data. The consequent information isolation brings potential risks to the enterprise management. At present, many enterprises haven't set up their own database, which poses challenges in data collection, management and comprehensive application, so they cannot provide strong data support for the integration of business and finance.

\section{Ineffective integration of business activities and financial management}

Enterprises should make use of the Internet Plus technology, to conduct the financial accounting before, amid and after the business activities, which requires financial staff to grasp the business process in advance. At present, many enterprises lack effective integration of business processes and financial processes, and there are conflicts of interest between business departments and financial departments. As a result, financial personnel are not familiar with the preliminary work of enterprise business, so they cannot get involved in the business processes and realize the whole-process monitoring of business work. Good effects achieved by the financebusiness integration are that the efficiency of financial work is greatly improved, and the workload of financial personnel is increased. Financial staff do not have enthusiasm to provide financial information and decision support for business activities in a timely manner, which make enterprise management decision lacks rationality and timeliness.

\section{The shortage of compound financial personnel influences the quality of business-finance integration}

In the process of business and finance integration, financial staff should shift their role from accounting to advisor to support the management decision of the enterprise and create value for the enterprise. This is a challenge for traditional financial professionals as they should not only master basic accounting theory and knowledge, but should also be proficient in the tools and methods in the field of management accounting. For better integration, financial personnel should also have good communication and leadership skills, and get familiar with information technology. However, currently, many financial personnel can't meet the requirements. Their overall poor-quality impact the smooth fusion process and its quality.[3]

\section{E. High cost to realize the in-depth integration of finance and business}

The implementation of the integration of business and finance will generate high costs. To realize the deep integration, enterprises need to establish their own information system, which not only requires advanced technologies and financial support, but also needs the financial personnel with rich reserve of knowledge and high level in operation. Additionally, corresponding functional departments need to be established and the training for the staff should be carried out in enterprises. All these put a high demand on fund, resulting in a no small expenditure for the enterprise. As a consequence, based on the cost-benefit principle, a lot of small- and medium-sized companies did poor in the application and implementation of the finance and business integration. Fortunately, there are indeed some companies boasting a relatively complete management accounting system. They are generally the enterprise groups with abundant capital capacity, such as China South Industries Group Corporation and Haier Group, or the communication enterprises with strong technology support, like China Mobile Communications Group. [4]

\section{STRATEGIES ON IMPLEMENTING THE BUSINESS AND FINANCE INTEGRATION UNDER THE INTERNET PLUS}

\section{A. Set up Internet Plus thinking and create the favorable condition for business-finance integration}

Enterprises should actively develop Internet Plus thinking. Management should use future planning, and bear in mind the enterprise strategy to speed up the business-finance integration. Taking the business development and the operation situation of the enterprise as the starting point, build the basic system according to the needs of the integration, to realize the combination of enterprise business and financial goals. Enterprises also need to reform the performance evaluation mechanism to stimulate the enthusiasm and initiative of business personnel and financial personnel to participate in the integration of industry and finance. In order to better implement the system, the enterprise should supervise the activities, guide and optimize business in a timely manner. In this way, the enterprise system can play its due role, and the business-finance integration environment can be constantly 
optimized, thus laying a good foundation for the long-term development of the enterprise and the achievement of the established business goals.

\section{B. Strengthen the construction of information system to break the organizational barriers}

Against the backdrop of Internet Plus, enterprises need to accelerate the construction of information system, research and develop the business and financial system that can gather, assort and analyze the real time data in a timely manner. The application of the information system like Financial Shared Service Center, cloud procurement and cloud reimbursement, interconnect financial and business systems through the information sharing. In this way, there is clear of organization bulwark and information isolation, enabling the sharing of financial and business data. In the actual practice, many enterprises are building the Financial Shared Service Center, through which, several basic financial works like reimbursement, accounting and the management of revenues and expenditures can be accomplished, enabling the financial staff to get familiar with the business at the front-line position. In this way, they can directly control and collect front-end business data to integrate business and financial data for the better integration of business and finance. [5] In addition, the financial sharing center realizes the sharing and synchronous update of financial data and business data, and the data become traceable. All these are conducive to the timely financial analysis of financial personnel and better service for management decisions.

\section{Monitor the business with the information technologies}

Under the background of Internet Plus, enterprises should make full use of information technology, integrate big data with management accounting information system, and realize the decision-making support function of management accounting in analyzing the past events, controlling the present situation and making decisions in the future. In budget management ahead of the business, the preparation of the budget should rely on the information system to comprehensively collect financial data and business data, internal and external data. Make analysis on these data to strengthen the financial control ability. In terms of supervision, the financial department leverage the information system to obtain real-time business data, which can monitor the business performance of the enterprise in real time, and find problems and correct them in time. With regard to the feedback after the event, the financial sector adopts big data technology to conduct in-depth processing analysis, summarize the performance of business execution, provide feedback decision-making reference for business departments, and improve the management level of enterprises.

\section{Upgrade financial structure to cater to the business- finance integration}

With the business and finance integration, finance will make more use of information technology to penetrate into business activities. Therefore, it is necessary to transform the traditional functional financial organization to meet the needs of the integration. The China Unicom has divided corporate finance into strategic finance, shared finance and business finance. Strategic finance is a strategic management position for the strategic supporters of an enterprise, which enables financial staff to participate in the formulation of financial policies and systems at the future planning and strategic decision-making. As for the shared finance, we can enter the financial sharing center and conduct efficient financial work through information means. Business finance requires finance to take the initiative to join business activities, such as the business research and development, contract management, etc. Let the professional financial personnel control risks, improve the efficiency and effect of operation, so as to create more value for the enterprise.

\section{E. Improve the comprehensive quality of the business-finance integration team}

In the era of Internet Plus, enterprises should set up professional teams according to the actual process and specific needs of finance and business integration, and constantly improve the overall quality of the teams. In the Businessfinance integration, financial personnel will extend to the strategic planning, cost control, performance evaluation, risk control, and other fields. They should alter from after-event accounting to value creation role. Enterprises can speed up the integration by sending financial personnel to the business department or establishing business and financial department. It is also possible to build an integration team through social recruitment. At the same time, the enterprise training can be carried out to mainly cultivate the big data thinking of the members of the business-finance integration team, improve their comprehensive financial analysis ability, communication and coordination ability, information technology processing capability, risk management and control ability, etc., so that they can meet the needs of business-finance integration. [6]

\section{CONCLUSION}

In the era of Internet Plus, the deep integration of business and finance is the only way to improve the financial management level of Chinese enterprises, no matter from the background of the Times or from the perspective of their own needs. Only by following this trend can enterprises survive in the new era. Future finance should be integrated and connected with business. Financial personnel needs to realize the limitations of traditional financial accounting, and constantly improve their own comprehensive quality, set up big data thinking, make full use of information technology to achieve the target fusion, personnel integration, data combination, etc., so as to transform to management accounting for the business-finance integration. In this way, they can still maintain their competitive advantage in the new era. Of course, this integration cannot be accomplished overnight, and enterprises should start from their own specific conditions, and gradually establish and improve the business and finance integration system. 


\section{REFERENCES}

[1] Zuo Rui, Wen Jing. On the In-depth Integration of Business and Finance Based on the Background of Big Data, Commercial Accounting[J]. 2017(8):38-40.

[2] Tang Guliang, Xia Yifei, The Theoretical Framework and Practical Essentials of Business and Finance Integration in Enterprise, Financial Accounting Analysis[J]. 2018(3):3-9.

[3] Guo Yongqing, On the Business and Finance Integration of Chinese Enterprises, Friends of Accounting[J]. 2017(7):47-55.
[4] Wang Jian, Wang Shuxia, On Management Accounting Based on Integration of Business and Finance -- A Case Study of China United Network Communications Limited, Financial Accounting Analysis[J]. 2017(8):109-112.

[5] Zhang Qinglong, On the Condition and Path of the Integration of Business and Finance, The Chinese Certificated Public Accountant [J]. 2018(1):109-112.

[6] Zhou Jie, Construction of Enterprise Management Accounting Application System Based on the Integration of Finance and Business, Commercial Accounting[J]. 2018(2):74-76 